Article

\title{
Experimental Investigation on Air-Water Interaction in a Hydropower Station Combining a Diversion Tunnel with a Tailrace Tunnel
}

\author{
Wen Zhang *, Fulin Cai, Jianxu Zhou and Yulong Hua \\ College of Water Conservancy and Hydropower Engineering, Hohai University, Nanjing 210098, China; \\ flcainj@163.com (F.C.); jianxuzhou@163.com (J.Z.); damienh@126.com (Y.H.) \\ * Correspondence: linketracy@126.com; Tel.: +86-150-505-88713
}

Academic Editor: Michele Mossa

Received: 18 February 2017; Accepted: 6 April 2017; Published: 13 April 2017

\begin{abstract}
Diversion tunnels are often used as tailrace tunnels in underground hydropower stations. The special layout results in complex flow regimes, including air-water two-phase flow. A set of experiments is conducted based on the model of a hydropower station which combines partial diversion tunnels with tailrace tunnels to investigate the interactions between the air and water phases in the combined diversion tunnels. Interactions between the air and water phases observed in the combined diversion tunnel significantly alter flow dynamics, and are classified into four types according to the initial tail water level. There is a range of initial tail water levels in which the interaction between the air and water phases cannot be neglected, and the range becomes greater when the change in flow rate increases. Such interactions may cause a pressure surge and the pressure surge reaches the maximum when the initial tail water level is approximately equal to the crown of the tunnel. The surge pressures do harm to the safety and stability of hydropower stations, so the condition should be considered and controlled.
\end{abstract}

Keywords: air-water interaction; hydropower station; tailrace tunnel combined with diversion tunnel; transient flow; pressure oscillation patterns

\section{Introduction}

The hydraulic phenomena in the tailrace systems of hydropower stations, the urban storm-sewer systems, and the long-distance water delivery systems may be complex for there can be three flow regimes [1-3]: pressure flows, free-surface flows, and mixed free-surface-pressure flows. When the mixed free-surface-pressure flows emerge, the pipelines of the tailrace system are partially full, which means pressure flow and free-surface flow occur simultaneously. During the hydraulic transient, air is entrapped and the interactions between the air and water phases influence the flow dynamics, which can act as a trigger for severe pressure surges and the sudden release of air-water mixtures $[4,5]$.

The work by Hamam and McCorquodale [6] and Li and McCorquodale [7] presented that the formation of air pockets was due to the relative motion of the air and water phases. Zhou et al. [8] considered air pockets that were entrapped during rapid filling owing to poor ventilation, according to the experimental observations. Vasconcelos and Wright [9] proposed that air pressurization played an important role in the formation of air pockets. The formation of the air pocket presented by Ferreri et al. [10] was attributed to a progressive accumulation of air entrained by the foamy front as it advanced, instead of the evolution of free-surface instability.

Interactions between the air and water phases significantly alter the dynamics of the water flowing in hydraulic systems [11]. Vasconcelos and Wright [9] classified the interactions between the two phases during the rapid filling process into five types. It was illuminated that the initial 
water level was the controlling variable in determining the type of interaction owing to the different ventilation. The current software and models are unable to simulate the mixed flow adequately, due to a series of assumptions and simplifications on the air phase effect [12]. Greater insight on physical mechanisms of air-water interactions is required. In recent years, scholars have paid more attention to sudden air pocket entrapment during the rapid filling in urban rainwater pipeline systems. Several experiments were carried out aiming to investigate some aspects of the transient. It was confirmed that the high-frequency pressure fluctuation was produced by the pulsations of trapped air $[7,10]$. Physical investigations by Lewis et al. $[13,14]$ focused on the significant water lift through vertical shafts attributed to air-water interactions. Padulano et al. [15] studied the working conditions of a vertical drop shaft, with and without a venting system. Bousso et al. [16] studied the effect of air pockets on the depressurization wavefront. The work mentioned above shed some light on the air-water two-phase flow in tailrace systems of hydropower stations. However, simplified physical models constructed in investigations for sewer systems may not reproduce key elements of hydropower stations. Experimental situations were run to reproduce the phenomena during the transition from free-surface flow to pressure flow in sewer systems, while hydropower stations underwent more situations. In addition, according to Vasconcelos and Wright [9], the impact of geometric variables defining a particular system was not negligible. Tunnels are usually horseshoe-shaped in tailrace systems while the cross-sections of the pipes in sewer systems are circular or square in previous studies $[17,18]$. Underlying physical investigations of air-water interactions are still required as most previous physical experiments were conducted to verify the design and numerical models. Physical understanding of air behavior in water pipes, which is helpful for further development of air management, is still a challenging question [19].

To make a further study of air-water interactions during the transition in a hydropower station combining a diversion tunnel with a tailrace tunnel, a series of experiments was conducted. Interactions between the air and water phases in the system subject to different combinations of changes in flows and initial tail water levels are systematically investigated. The interactions are classified into four types according to their dynamic characteristics and the flow conditions that led to the occurrence of these interactions are described. The pressure oscillation patterns and maximum pressures are presented, respectively, for each type of interactions.

\section{Methodology}

\subsection{Experimental Apparatus}

The model conducted in this experiment consisted of an upstream reservoir, water intakes, inlet gates, pressure pipes, spiral cases, draft tubes, draft tube gate shafts, an impedance surge chamber $70 \mathrm{~cm}$ in diameter, tailrace tunnels, a ventilation shaft $5 \mathrm{~cm}$ in diameter, a tailrace gate shaft, the tailrace channel, and a partial downstream river channel. The experimental apparatus is described in Figure 1. Table 1 lists the parameters of the pipelines in the water diversion system and tailrace system. The whole system was made of polymethyl methacrylate (PMMA) except the upstream reservoir and downstream channel, making it easy to observe the flow phenomena.

The turbine modelled in the experiments was a simplified Francis turbine. The runner was replaced by a needle-valve throttle device, and we operated the turbine by closing or opening the needle-valve.

A capacious steel water tank was constructed to simulate the upstream reservoir, so that the disturbance from the inflow could be ignored. The tailrace tunnel terminal was connected to a large enough channel built to simulate the river-way downstream. The steel water tank and the downstream channel were provided with overflow devices to control the water level by adjusting the spill level. The initial water level in the downstream channel was varied in order to determine its impact on the interaction between the air and water phases. The initial water level in the upstream reservoir was nearly constant. Flow was admitted through the inflow pipes connected to the upstream reservoir. 
The flow rate of each unit was regulated by the upstream flow control valve. Ultrasonic flow meters were installed to gauge the flow rates of the units, as well as real-time monitoring. The initial relative flow of the second unit was also a variable in the experiment. The change in flow of the main tailrace tunnel (load rejection) was achieved via closing the needle-valve throttle device located at the second unit. The needle-valve throttle device was developed by the Hydroelectric Power Testing and Research Center in Hohai University. There may be three ventilation points in the system: the ventilation shaft, the third gate shaft, and the outlet of the tunnel. When the water level at the ventilation point was lower than the elevation of tunnel crown, air flowed into the tunnel. The number of ventilation points varied under different combinations of flow rate and water levels because of the different fluctuations of water levels.

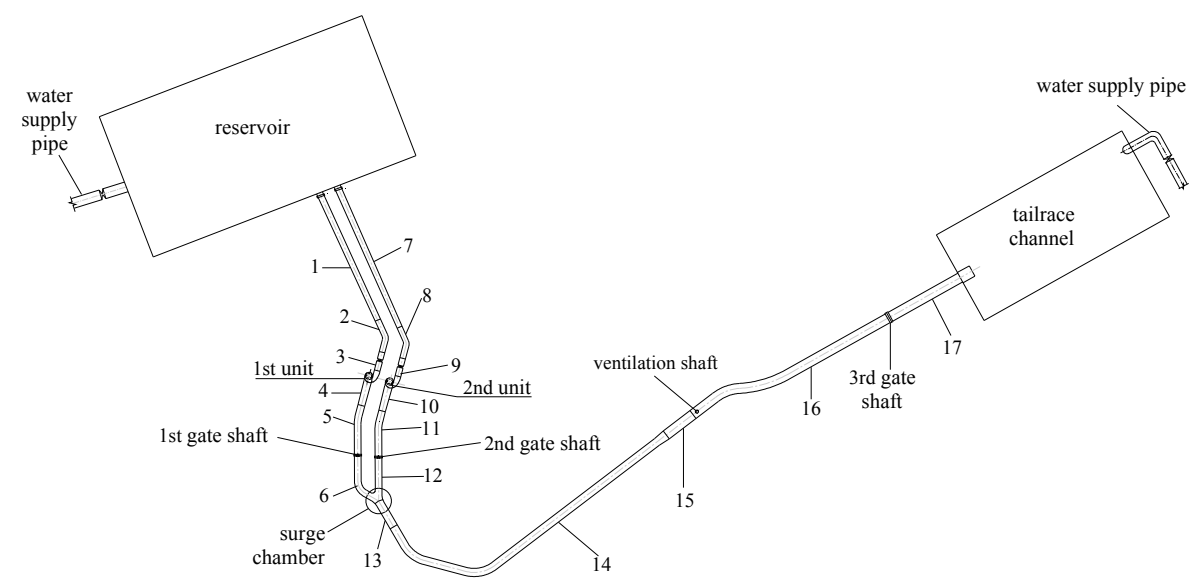

(a)

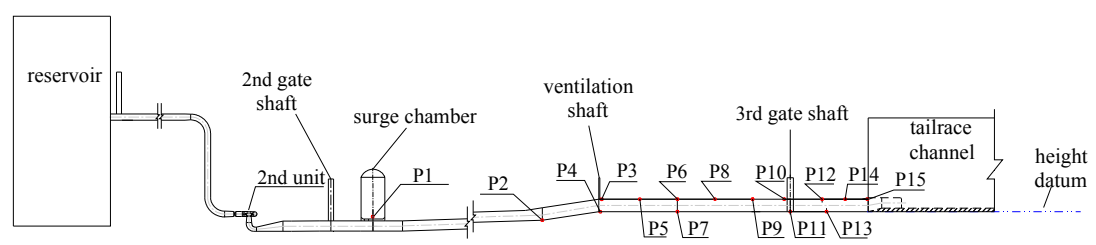

(b)

Figure 1. Arrangement of the experimental model: (a) plan view and (b) longitudinal section along the center line of the second hydraulic unit.

Table 1. Parameters of the pipelines in the model.

\begin{tabular}{|c|c|c|c|c|c|}
\hline & No. & Range of Pipelines & Length $(\mathrm{m})$ & $\begin{array}{c}\text { Sectional Area } \\
\left(\mathrm{m}^{2}\right) \cdot 10^{-3}\end{array}$ & Discharge \\
\hline \multirow{6}{*}{ First unit } & 1 & Water intake to upstream end of upper curved pipe & 4.22 & 26.35 & \multirow{6}{*}{$Q_{1}{ }^{a}$} \\
\hline & 2 & Upstream end of upper curved pipe to downstream end of lower curved pipe & 3.43 & 22.70 & \\
\hline & 3 & Downstream end of lower curved pipe to the first unit & 0.50 & 18.32 & \\
\hline & 4 & First draft tube (along the center line) & 1.35 & 28.65 & \\
\hline & 5 & End of the first draft tube to the center line of the first gate shaft & 1.45 & 65.06 & \\
\hline & 6 & Center line of the first gate shaft to the center line of the surge chamber & 1.75 & 60.00 & \\
\hline \multirow{6}{*}{ Second unit } & 7 & Water intake to upstream end of upper curved pipe & 4.54 & 26.35 & \multirow{6}{*}{$Q_{2}^{b}$} \\
\hline & 8 & Upstream end of upper curved pipe to downstream end of lower curved pipe & 3.43 & 22.70 & \\
\hline & 9 & Downstream end of lower curved pipe to the second unit & 0.50 & 18.32 & \\
\hline & 10 & Second draft tube (along the center line) & 1.35 & 28.65 & \\
\hline & 11 & End of the second draft tube to the center line of the second gate shaft & 1.45 & 65.06 & \\
\hline & 12 & Center line of the second gate shaft to the center line of the surge chamber & 1.28 & 60.00 & \\
\hline \multirow{5}{*}{$\begin{array}{c}\text { Main tailrace } \\
\text { tunnel }\end{array}$} & 13 & Center line of surge chamber to the downstream end of the transition section & 0.88 & 71.30 & \multirow{5}{*}{$Q_{0}{ }^{c}$} \\
\hline & 14 & Tunnel with a slope of 0.035 & 10.07 & 68.59 & \\
\hline & 15 & Linking tunnel with a slope of 0.15 & 1.67 & 99.82 & \\
\hline & 16 & Downstream end of the linking tunnel to the center line of the third gate shaft & 5.65 & 99.82 & \\
\hline & 17 & Center line of the third gate shaft to the outlet & 2.30 & 100.20 & \\
\hline
\end{tabular}

Notes: ${ }^{a} Q_{1}=$ the initial flow rate of first hydraulic turbine unit, ${ }^{\mathrm{b}} Q_{2}=$ the initial flow rate of second hydraulic turbine unit, ${ }^{c} Q_{0}=$ the initial flow rate of main tailrace tunnel $=Q_{1}+Q_{2}$. 
Fifteen pressure sensors (P1-P15) were installed along the tailrace system and they were listed in Table 2, as well as marked in Figure 1. The data was collected by the computer automatically. Pressure histories were recorded with a sampling frequency of $256 \mathrm{~Hz}$.

Table 2. Layout of pressure sensors.

\begin{tabular}{ll}
\hline Pressure Sensors & \multicolumn{1}{c}{ Location } \\
P1 & Above the surge chamber floor \\
P2 & At the bottom of the upstream end of tunnel 15 \\
P4 & At the top of tunnel 16 adjacent to ventilation shaft \\
P5 & At the bottom of tunnel 16 under ventilation shaft \\
P6 & At the top of tunnel 16, 1.16 m downstream from ventilation shaft \\
P7 & At the top of tunnel 16, 2.27 m downstream from ventilation shaft \\
P8 & At the bottom of tunnel 16, 2.28 m downstream from ventilation shaft \\
P9 & At the top of tunnel 16, 3.38 m downstream from ventilation shaft \\
P10 & At the top of tunnel 16, 4.49 m downstream from ventilation shaft \\
P11 & Close to the upstream side of the third gate shaft \\
P12 & At the bottom of tunnel under the third gate shaft \\
P13 & At the top of tunnel 17, 0.85 m downstream from the third gate shaft \\
P14 & At the bottom of tunnel 17, 1.07 m downstream from the third gate shaft \\
P15 & At the top of tunnel 17, 1.53 m downstream from the third gate shaft \\
\hline
\end{tabular}

\subsection{Experimental Conditions and Procedure}

The runs (listed in Table 3) were organized in four groups (denoted as 1-4), according to the different combinations of flow rates. For groups 1-4, the initial flow rate of the main tailrace tunnel $Q_{0}$ was constant, with different allocation of $Q_{1}$ and $Q_{2}$. The experiment was initiated by closing the needle-valve, implying the whole load of the second unit was rejected. One of the crucial variables of the four groups was the flow rate $Q_{2}$ which would be lost to change the total flow rate of the main tailrace tunnel.

Table 3. The experimental groups.

\begin{tabular}{cccccc}
\hline Groups & The Upstream Water Level & $Q_{\mathbf{1}}(\mathrm{L} / \mathbf{s})$ & $Q_{\mathbf{2}}(\mathrm{L} / \mathbf{s})$ & $Q_{\mathbf{0}}(\mathrm{L} / \mathbf{s})$ & $Q_{2}{ }^{*}\left(=Q_{2} / Q_{0}\right)$ \\
\hline 1 & & 9 & 21 & 30 & 0.7 \\
2 & constant & 12 & 18 & 30 & 0.6 \\
3 & & 15 & 15 & 30 & 0.5 \\
4 & & 18 & 12 & 30 & 0.4 \\
\hline
\end{tabular}

Moreover, a series of tests was performed with varied initial tail water levels in each group, which was the other crucial variable discussed. The initial tail water level was given in the form of a relative value ranging from 0.75 to 1.2 to show the initial flow state in the combined diversion tunnel directly-pressure flow or free-surface flow.

The different combinations of the two variables represented the different possible working conditions.

The experiments were carried out according to the following procedure:

1. The upstream water supply pump was started and then the upstream inlet valve was opened to feed the steel water tank. The overflow level of the upstream reservoir was adjusted so that the upstream water level was maintained at a constant value of $3.45 \mathrm{~m}$ above the floor of the main tailrace tunnel throughout the experiments.

2. The overflow device in the downstream channel was adjusted to achieve the desired tail water level in accordance with the test conditions. 
3. After closing the first flow control valve, the second flow control valve was adjusted to achieve the desired flow rate $Q_{2}$. The flow rate $Q_{2}$ was measured by an ultrasonic flow meter and checked according to the discharge of the triangular-notch, thin-plate weir downstream.

4. When the flow reached steady-state, the first flow control valve was opened and adjusted to achieve the desired flow rate $Q_{1}$. The flow rate $Q_{1}$ was also measured by an ultrasonic flow meter and verified by the difference between the discharge of the triangular-notch, thin-plate weir downstream and $Q_{2}$.

5. The downstream supplement valve was opened and adjusted to a proper flow rate to simulate the flow of the downstream river, maintaining the tail water level constant during the transition.

6. When the flow reached a steady-state, the needle-valve of the second unit was closed with the closing time of about $2 \mathrm{~s}$. Pressure histories were recorded synchronously.

7. The flow phenomenon was observed and filmed, especially the interactions of air and water and the evolution of air pockets.

8. Data recording was stopped when the flow reached a new steady-state, and the needle-valve was opened.

9. When the flow was stable, steps 2-8 were repeated to perform the next run.

The following non-dimensional variables are defined to present the results:

$$
Q_{2}{ }^{*}=Q_{2} / Q_{0}, y^{*}=y / H_{\mathrm{d}}, h^{*}=H / H_{\mathrm{d}}
$$

in which $Q_{2}$ is the initial flow rate of second hydraulic turbine unit, $Q_{0}$ is the initial flow rate of the main tailrace tunnel, $y$ is the initial tail water depth, $H_{\mathrm{d}}$ is the height of tunnel 17 , and $H$ is the pressure head.

\section{Results and Discussion}

\subsection{Effect of Initial Tail Water Level on Interaction between the Air and Water Phases}

For each group, the value of $y^{*}$ varied from 0.75 to 1.2 resulting in different flow regimes. For greater values of $y^{*}$, flow in the whole system maintained the state of pressure flow during the transition process. Air admission was observed indicating that air-water two phase flow occurred when the value of $y^{*}$ decreased to a specified level. Several different interactions between the air and water phases were observed when the value of $y^{*}$ varied.

\subsubsection{Definition of Three Critical Relative Tail Water Depths}

In order to illustrate the different air-water interactions observed at different tail water levels, three critical relative tail water depths are defined so that the initial tail water levels can be divided into several intervals. In each interval, a specific flow feature was observed with the distinct air-water interaction.

The critical relative tail water depths are defined as follows:

1. Intake Critical Relative Tail Water Depth $y_{1}$.

The initial steady-state in the whole system is the pressure flow and the water level in the ventilation shaft is higher than the elevation of the tunnel crown. The water level in ventilation shaft fluctuates as the flow varies. If the lowest surge level in the ventilation shaft is just flush with the elevation of tunnel crown during the transition process, as shown in Figure 2a, the corresponding initial relative tail water depth is defined as the "intake critical relative tail water depth" $y_{1}$ *.

\section{Single Air Pocket Critical Relative Tail Water Depth $y_{2}{ }^{*}$.}

The initial steady-state in the combined diversion tunnel is pressure flow and the water level in the ventilation shaft is higher than the elevation of the tunnel crown. The water level in the ventilation 
shaft fluctuates as the flow varies and, when it falls below the elevation of tunnel crown, air flows in and forms only one air pocket, as shown in Figure $2 \mathrm{~b}$. The lowest relative initial tail water depth, which can ensure that only one air pocket is entrapped and the flow pattern shown in Figure $2 \mathrm{c}$ will not be observed during the transition process, is defined as the "single air pocket critical relative tail water depth" $y_{2}{ }^{*}$.

\section{Interface Instability Critical Relative Tail Water Depth $y_{3}$.}

The initial steady flow in the combined diversion tunnel is a free-surface flow. The water level in the tunnel fluctuates as the flow varies. If the highest surge level is just equal to the elevation of the tunnel crown, as shown in Figure 2c, during the transition process, the corresponding initial relative tail water depth is defined as the "interface instability critical relative tail water depth" $y_{3}{ }^{*}$.

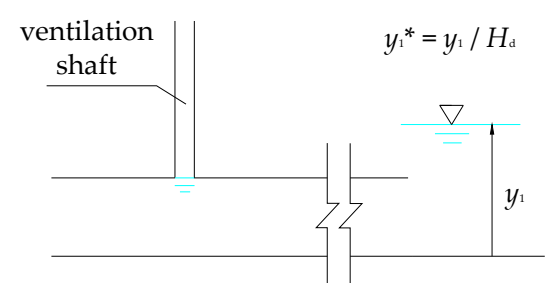

(a)

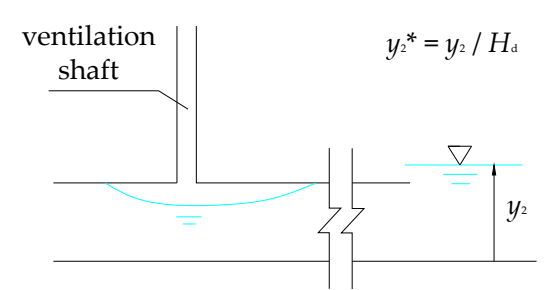

(b)

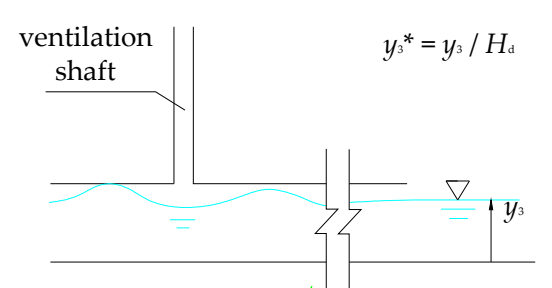

(c)

Figure 2. The critical relative tail water depth: (a) the intake critical relative tail water depth $y_{1}^{*} ;(\mathbf{b})$ the single air pocket critical relative tail water depth $y_{2}{ }^{*}$; and (c) the interface instability critical relative tail water depth $y_{3}^{*}$.

\subsubsection{The Type of Interactions between the Air and Water Phases}

When the downstream initial relative tail water depth $y^{*}$ was greater than $y_{1}{ }^{*}$, the entire hydraulic system was always in a pressure state during the transition. Conversely, if the downstream initial relative tail water depth $y^{*}$ was less than $y_{1}^{*}$, air admission was observed, indicating the occurrence of a mixed flow. For each group, interactions between the air and water phases observed in the combined diversion tunnel could be classified into four types according to the value of $y^{*}$.

\section{Single Air Pocket Motion}

When the downstream initial relative tail water depth $y^{*}$ ranged from $y_{1}{ }^{*}$ to $y_{2}{ }^{*}\left(y_{2}{ }^{*}\right.$ was included), air flowed in through the ventilation shaft and an air pocket formed after the needle-valve of the second unit was closed. The main characteristic of the phenomenon was that only one air pocket was observed without fracture during the expansion and compression cycle. Water flowed downstream initially 
because of inertia when the flow was reduced, resulting in a falling water level in the ventilation shaft. Air flowing in through the ventilation shaft attributed to a pressure drop and mainly expanded downstream. The air front was almost vertical, initially, and then a small wave formed behind the air front caused by the relative motion of the air and water phases during the first air expansion. Then air was released at the ventilation shaft when it was compressed. This process was repeated until the flow reached a new stable-state. The volume of the air pocket was the largest during the first expansion and became smaller in the later cycles. The air pocket migrated downstream with the water flow as it became smaller, and was usually trapped at the top of the tunnel downstream of the ventilation shaft.

\section{Multiple Air Pockets Motion}

If $1 \leq y^{*}<y_{2}{ }^{*}$, the tailrace system was initially in a full pressure state. In this condition, the flow pattern was very complex due to the uncertain ventilation. Air flowed in through the ventilation shaft simply and an air pocket formed at a greater value of $y^{*}$. The air pocket expanded and fractured because the wave behind the air front, described as the "single air pocket motion", reached the crown of the tunnel. The small air pockets separated moved downstream and escaped through the third gate shaft. When the value of $y^{*}$ was smaller, air would also flow in through the third gate shaft, and another air pocket formed expanding both upstream and downstream. A collision was created when the advancing air fronts of the two pockets met, resulting in several waves. The waves reached the crown and small air pockets were entrapped. The air pockets were compressed, giving rise to the sudden release of air-water mixtures occurring at the ventilation shaft and the third gate shaft. The main characteristic of the motion was that several air pockets were observed undergoing collision and fracture. The flow reached a new stable-state flow finally, and a large air pocket was trapped at the top of the tunnel downstream of the ventilation shaft, while the smaller ones migrated downstream and escaped through the third gate shaft.

\section{Interfacial Instability}

If $y_{3}{ }^{*} \leq y^{*}<1$, the initial flow regime in the tailrace system transitioned from a pressure flow to a free-surface flow. When the water level in the tailrace tunnel dropped, air flowed in through the ventilation shaft, the third gate shaft, and the outlet of the tunnel. Due to adequate ventilation, air pressure above the free-surface of the water was basically maintained at atmospheric pressure, and the free-surface fell with a more or less uniform rate. As the flow reversed, the area of ventilation decreased with the rising free-surface, leading to an acceleration of the air flow rate and uneven pressurization of the air layer above the free-surface. The relative motion of the air and water phases and the uneven air pressure resulted in the evolution of free-surface instability. Waves formed and then reached the crown of the tunnel making the tunnel partially full. Air pockets formed as air was trapped between the adjacent waves without an obvious law of the location and number. The main characteristic of the motion were the large oscillations of the free-surface and the waves of the free-surface reaching the crown.

\section{Negligible Interaction}

This type of interaction was observed when the value of $y^{*}$ was reduced to less than $y_{3}^{*}$. The main characteristic of the motion was that oscillations of the free-surface were too small to reach the crown. There was a definite interface between the pressure flow and the free-surface flow, from which the flow was a pressure flow upstream and a free-surface flow downstream. It should be noticed that the interface is not vertical. During the process of transition, the ventilation shaft, the third gate shaft, and outlet of the tunnel all played a role in adjusting the air pressure above the free-surface.

\subsection{Effect of Change in Flow on Interactions between the Air and Water Phases}

It has been confirmed that $y^{*}$ is the controlling variable in determining the type of interactions for each experimental group in the previous section. Four experimental groups involving different 
decreases in flow were performed to assess possible effects on the interactions between the air and water phases. The effect can be obtained indirectly by its influence on the values of critical relative tail water depths presented in Table 4 for each group.

Table 4. The critical relative tail water depths.

\begin{tabular}{ccccc}
\hline \multirow{2}{*}{ Critical Relative Tail Water Depths } & \multicolumn{4}{c}{ Groups } \\
\cline { 2 - 5 } & $\mathbf{1}$ & $\mathbf{2}$ & $\mathbf{3}$ & $\mathbf{4}$ \\
\hline$y_{1}{ }^{*}$ & 1.146 & 1.130 & 1.111 & 1.086 \\
$y_{2}{ }^{*}$ & 1.100 & 1.089 & 1.073 & 1.059 \\
$y_{3}{ }^{*}$ & 0.885 & 0.895 & 0.909 & 0.931 \\
\hline
\end{tabular}

A conclusion can be drawn from the outcomes of the four groups that the values of $y_{1}{ }^{*}$ and $y_{2}{ }^{*}$ increase with the increasing value of $Q_{2}$, whereas the value of $y_{3}{ }^{*}$ decreases. Therefore, air flows in at a higher initial tail water level, and the wave reaches the crown of the combined diversion tunnel at a lower initial tail water level for the run with a greater value of $Q_{2}$. The results indicate that the range of the initial tail water levels at which the interactions between the air and water phases cannot be neglected is greater, and so is the range of the initial tail water levels at which the mixed flow occurs.

When the value of $Q_{2}$ is greater, the flow rate decreases faster after the needle-valve is closed, leading to the smaller value of the lowest water level. Hence, the value of $y_{1}{ }^{*}$ becomes smaller when the value of $Q_{2}$ decreases. Similarly, when the value of $Q_{2}$ is greater, the wave formed behind the air front will be higher due to the more drastic relative motion of the air and water phases for the single air pocket motion. Thus, the value of $y_{2}{ }^{*}$ becomes smaller when the value of $Q_{2}$ decreases. Furthermore, the water level drops to a lower value when the value of $Q_{2}$ is greater, making the driving head greater as the tail water level remains almost unchanged. The greater driving head brings about more rapid inverse flow and the greater value of the maximum water level in the surge chamber, as well as in other portions. The higher water level results in poor ventilation which, more or less, exacerbates the oscillation of the free-surface. Thus, the value of $y_{3}{ }^{*}$ increases with the decreasing value of $Q_{2}$.

In summary, for a hydropower station, the interactions between the air and water phases will be observed at a higher initial tail water level when the change in flow increases with a constant initial flow rate of the main tailrace tunnel. At the same time, the water level region for the flow pattern of interfacial instability obviously increases.

The types of interactions between the air and water phases observed in the combined diversion tunnel depend on the value of $y^{*}$, in agreement with the previous literature findings [7,9]. Hatcher and Vasconcelos [20] reported that the flow rate affected the air pocket volume and the maximum pressure head. The change in flow is another experimental variable studied in our experiments. The results indicate that the change in flow has an effect on the types of interactions, different from the results of Vasconcelos and Wright [9].

\subsection{Pressure Oscillation Patterns}

The pressure fluctuations over time along the pipelines of the tailrace system were recorded, except for the qualitative observation of air-water interactions under different combinations of varied flows and water levels. The data was collected to give some reasonable suggestion to the required capabilities of numerical models and the control conditions of design. The different pressure oscillation pattern and maximum pressures when two-phase flow occurs are presented in this section.

Pressure oscillations at several monitoring points are given from Figures 3-6 to illustrate the effect of the air phase under different air-water interactions. 


\section{Single Air Pocket Motion}

A single air pocket formed undergoing expansion and compression in this motion, and could be as long as $2 \mathrm{~m}$. Figure 3 shows the pressure oscillations in the combined diversion tunnel when $y^{*}=1.086$ and 1.073. The oscillations are superimposed by a low-frequency oscillation due to the flow change and a high-frequency oscillation due to the expansion and compression of the air pocket. For the same group (Figure 3a,b), the high-frequency oscillation becomes more intense as the initial tail water level decreases. The low-frequency oscillation dominates, and the pulsation of the air pocket does not cause significant pressurization as the maximum pressures in Figure $3 \mathrm{a}, \mathrm{b}$ are nearly the same. It can be gained that the high-frequency oscillation is weakened for a smaller variation of the flow rate with the same initial tail water level by comparing Figure $3 b, c$.

\section{Multiple Air Pocket Motion}

The pressure oscillations in the combined diversion tunnel are still superimposed by a low-frequency oscillation due to the flow change and a high-frequency oscillation due to the air pockets. The collision and fracture of air pockets cause a pressure surge inside the tunnel. In addition, the sudden release of air-water mixtures occurring at the ventilation shaft and the third gate shaft also results in a significant increase in pressure and high-frequency oscillations shown in Figure 4. The high-frequency oscillation due to the pulsation of air pockets is more violent and the role of interactions between the air and water phases cannot be ignored. The pressure increment increases as the drop of initial tail water level in this case.

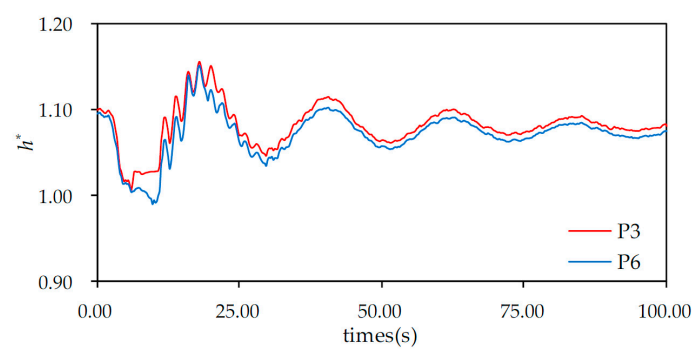

(a)

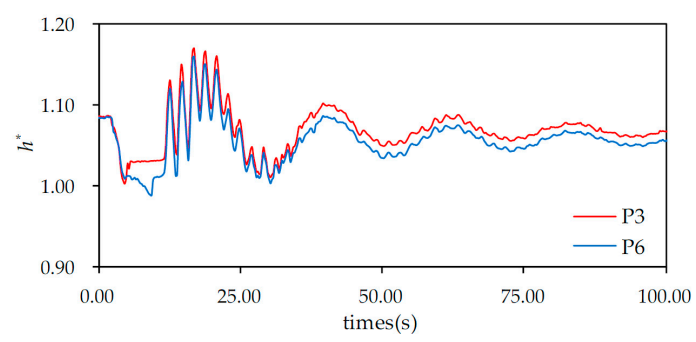

(b)

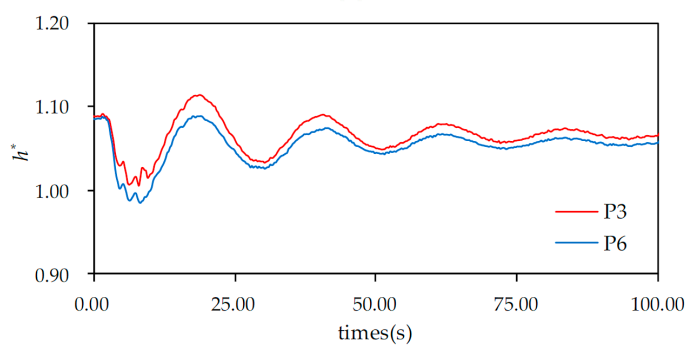

(c)

Figure 3. Pressure oscillation over time at P3 and P6: (a) when $y^{*}=1.086$, for group 2; (b) when $y^{*}=1.073$, for group 2 ; and (c) when $y^{*}=1.073$, for group 4 . 


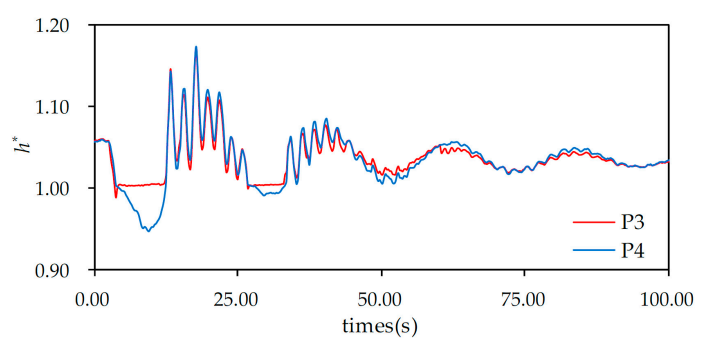

(a)

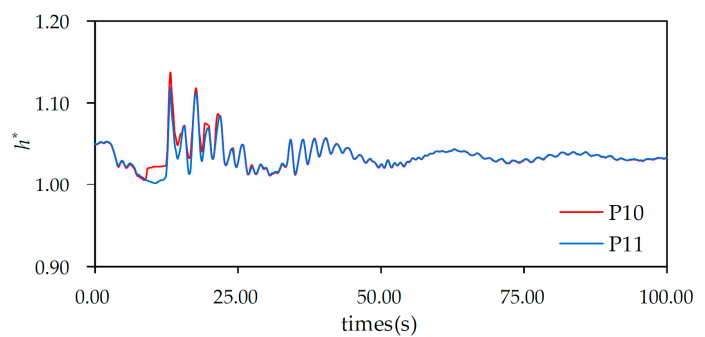

(b)

Figure 4. Pressure oscillation over time for group 2, when $y^{*}=1.047$ : (a) at P3 and P4, near the ventilation shaft, and (b) at P10 and P11, near the third gate shaft.

\section{Interfacial Instability}

Figure 5 shows the pressure oscillations measured at the top and bottom of the combined diversion tunnel near the ventilation shaft and the third gate shaft, respectively, for $y^{*}=0.963$. The red line represents the pressure fluctuation measured at the crown of the tunnel while the blue line represents the pressure fluctuation measured at the bottom. Large impact pressures are generated when the waves of the free-surface reach the crown of the tunnel. Subsequently, the collision and fracture of air pockets trapped between the adjacent waves cause high-frequency pressure oscillations. The maximum pressure is observed during the first impact. The air pressure above the free-surface is always maintained approximately at atmospheric pressure and no pressurization is observed until the wave peaks get close to the crown.

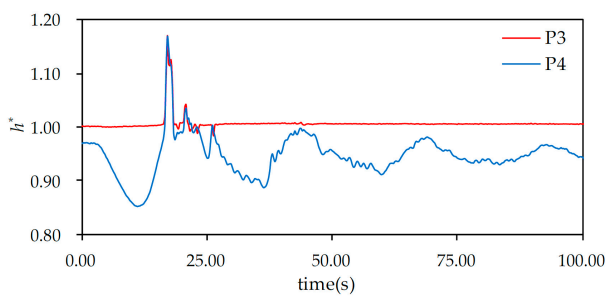

(a)

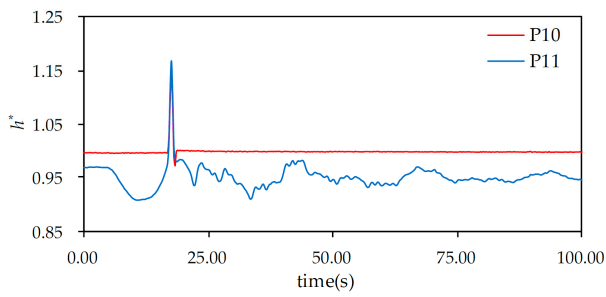

(b)

Figure 5. Pressure oscillation over time for group 2, when $y^{*}=0.963$ : (a) at P3 and P4, near the ventilation shaft; and (b) at P10 and P11, near the third gate shaft. 


\section{Negligible Interaction}

The pressure oscillations measured near the ventilation shaft and the third gate shaft, respectively, for $y^{*}=0.868$, when the interactions between the air and water phases can be ignored, are presented in Figure 6. The red line represents the pressure fluctuation measured at the crown of the tunnel. Throughout the transition, the curve is basically straight, revealing that the air pressure above the free-surface is always maintained at atmospheric pressure without significant fluctuation. The smooth blue line represents the pressure fluctuation measured at the bottom of the tunnel. Only low-frequency gravity waves were observed in the combined diversion tunnel.

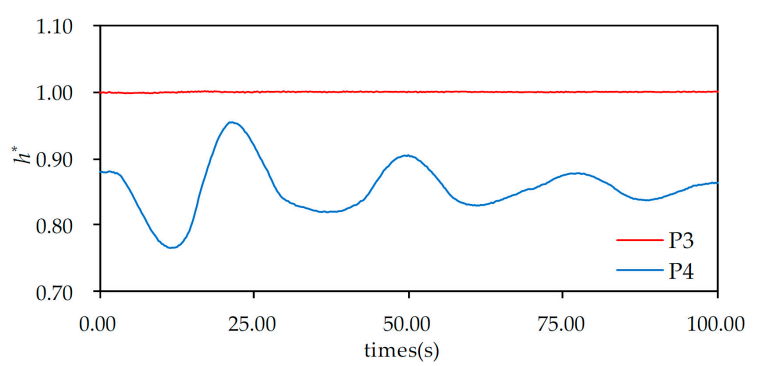

(a)

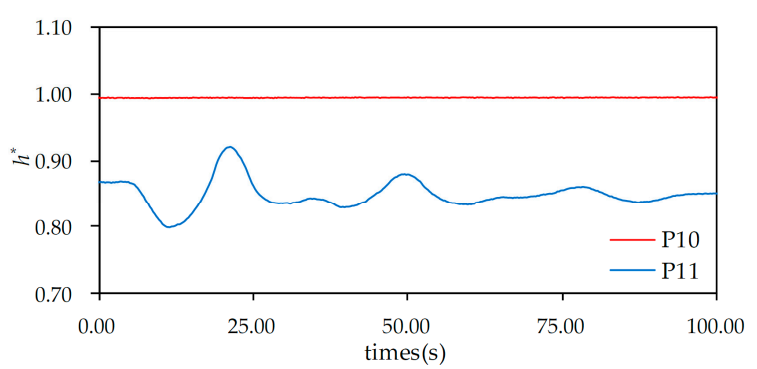

(b)

Figure 6. Pressure oscillation over time for group 2, when $y^{*}=0.868$ : (a) at P3 and P4, near the ventilation shaft; and (b) at P10 and P11, near the third gate shaft.

It can be concluded that the "multiple air pockets motion" condition and the "interfacial instability" condition have a critical effect on the maximum pressure during the transition. The relative maximum pressures of the combined diversion tunnel in the two conditions are plotted in Figure 7. Figure $7 \mathrm{a}-\mathrm{f}$ correspond to the results of six measuring points located on the crown of the combined diversion tunnel. When the initial relative tail water depth $y^{*}$ exceeds $y_{3}^{*}$, the type of interaction between the air and water phases is "interfacial instability ". In this case, the maximum pressure increases rapidly with the increase of the initial relative tail water depth $y^{*}$. When the initial relative tail water depth $y^{*}$ exceeds 1 , the "multiple air pockets motion" condition is observed. In this case, the maximum pressure at each measuring point decreases with the increase of the initial relative tail water depth $y^{*}$. For the condition that the interaction between the air and water phases is not negligible, the peak pressure in the tunnel reaches the maximum when the initial tail water level is approximately equal to the crown, which may become the key condition in the design. 


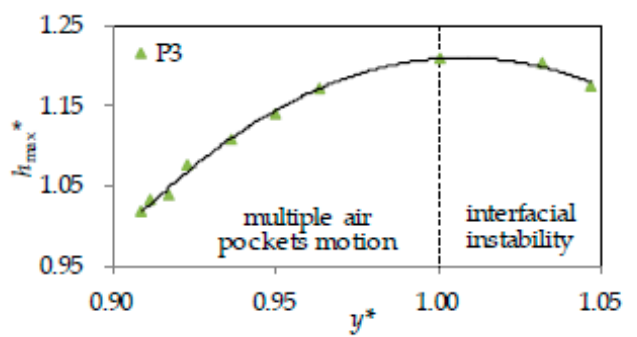

(a)

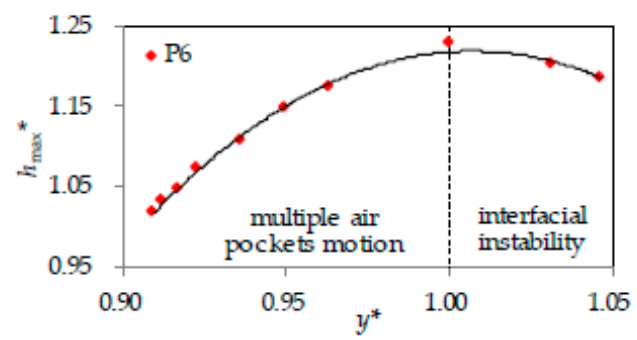

(c)

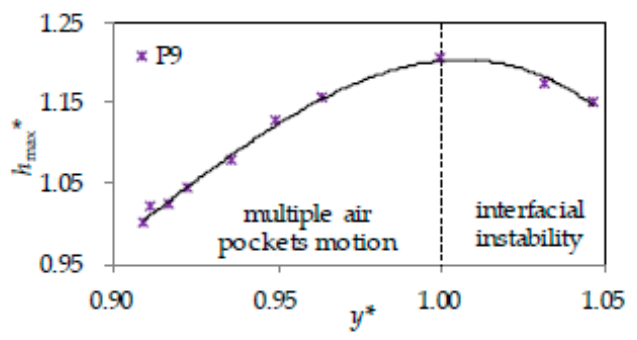

(e)

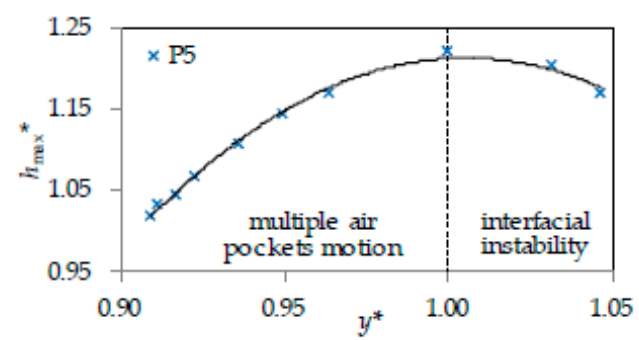

(b)

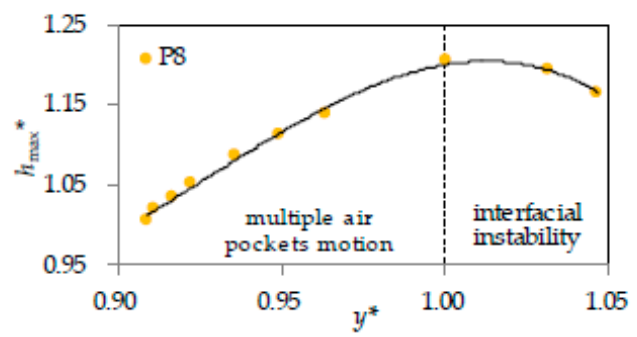

(d)

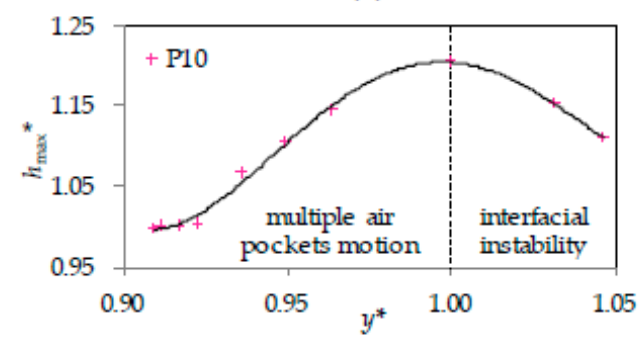

(f)

Figure 7. The relative maximum pressures of measuring points located on the crown for group 2: (a) at P3; (b) at P5; (c) at P6; (d) at P8; (e) at P9; and (f) at P10.

\section{Conclusions}

This work presents a systematic physical investigation on air-water interactions during the transition in a hydropower station combining a diversion tunnel with a tailrace tunnel. Four groups of experiments with different combinations of flow rates were carried out. Moreover, a series of tests was performed with variable initial tail water levels in each group. Interactions between the air and water phases in the system subject to different combinations of changes in flows and initial tail water levels are investigated. Several conclusions can be drawn from the outcomes.

Interactions between the air and water phases observed in the combined diversion tunnel could be classified into four types depending on the value of $y^{*}$. The four types are called "single air pocket motion", "multiple air pockets motion", "interfacial instability", and "negligible interaction". It is confirmed that $y^{*}$ is the controlling variable in determining the type of interactions.

Another experimental variable studied was the change in flow. When the change in flow is greater, air flows in at a higher initial tail water level and the wave reaches the crown of the combined diversion tunnel at a lower initial tail water level. This indicates that the range of initial tail water levels at which the interaction between the air and water phases cannot be neglected is greater.

The "multiple air pockets motion" condition and the "interfacial instability" condition have a critical effect on the maximum pressure during the transition. Pressure surges were observed under the two conditions. The peak pressure in the tunnel reaches the maximum when the initial tail water level is approximately equal to the crown of the tunnel. 
As the interactions between the air and water phases play an important role in conditions of the "multiple air pockets motion" and the "interfacial instability", a two-phase model may reproduce and predict the flow better. In addition, a run with the greater change in flow and the initial tail water level approximately equal to the crown of the tunnel may become the key conditions in the design, taking into account the maximum pressure.

Acknowledgments: The authors gratefully acknowledge the support from the Project Funded by the Priority Academic Program Development of Jiangsu Higher Education Institutions (PAPD, SYS1401) and Graduate Research and Innovation Program in Jiangsu Province (KYZZ16_0286). Thanks are due to Hydroelectric Power Testing and Research Center in Hohai University for assistance with the experiments.

Author Contributions: Fulin Cai and Jianxu Zhou initiated and supervised the study. Wen Zhang conceived and designed the experiments and performed the experiments with Yulong Hua, Wen Zhang drafted the manuscript.

Conflicts of Interest: The authors declare no conflict of interest.

\section{References}

1. Cheng, Y.; Li, J.; Yang, J. Free surface-pressurized flow in ceiling-sloping tailrace tunnel of hydropower plant: Simulation by vof model. J. Hydraul. Res. 2007, 45, 88-99. [CrossRef]

2. Zhou, J.; Su, Q.; Cai, F. Hydraulic characteristic analysis of changing top-altitude tail tunnel and its application. In Advances in Water Resources and Hydraulic Engineering: Proceedings of 16th Iahr-Apd Congress and 3rd Symposium of Iahr-Ishs; Zhang, C., Tang, H., Eds.; Springer: Berlin/Heidelberg, Germany, 2009; pp. 2074-2079.

3. León, A.S.; Liu, X.; Ghidaoui, M.S.; Schmidt, A.R.; García, M.H. Junction and drop-shaft boundary conditions for modeling free-surface, pressurized, and mixed free-surface pressurized transient flows. J. Hydraul. Eng. 2010, 136, 705-715. [CrossRef]

4. Guo, Q.; Song, C.C. Surging in urban storm drainage systems. J. Hydraul. Eng. 1990, 116, 1523-1537. [CrossRef]

5. Guo, Q.; Song, C.C. Dropshaft hydrodynamics under transient conditions. J. Hydraul. Eng. 1991, 117, 1042-1055. [CrossRef]

6. Hamam, M.A.; McCorquodale, J.A. Transient conditions in the transition from gravity to surcharged sewer flow. Can. J. Civ. Eng. 1982, 9, 189-196. [CrossRef]

7. Li, J.; McCorquodale, A. Modeling mixed flow in storm sewers. J. Hydraul. Eng. 1999, 125, 1170-1180. [CrossRef]

8. Zhou, F.; Hicks, F.; Steffler, P. Observations of air-water interaction in a rapidly filling horizontal pipe. J. Hydraul. Eng. 2002, 128, 635-639. [CrossRef]

9. Vasconcelos, J.G.; Wright, S.J. Experimental investigation of surges in a stormwater storage tunnel. J. Hydraul. Eng. 2005, 131, 853-861. [CrossRef]

10. Ferreri, G.B.; Ciraolo, G.; Lo Re, C. Storm sewer pressurization transient-An experimental investigation. J. Hydraul. Res. 2014, 52, 666-675. [CrossRef]

11. Wang, C.; Yang, J.; Nilsson, H. Simulation of water level fluctuations in a hydraulic system using a coupled liquid-gas model. Water 2015, 7, 4446. [CrossRef]

12. Bousso, S.; Daynou, M.; Fuamba, M. Numerical modeling of mixed flows in storm water systems: Critical review of literature. J. Hydraul. Eng. 2012, 139, 385-396. [CrossRef]

13. Lewis, J.; Wright, S.J.; Vasconcelos, J. Mechanisms for surges in vertical shafts in stormwater tunnels. J. Water Manag. Model. 2011. [CrossRef]

14. Lewis, J.; Wright, S.J. Air-water interactions that generate large water lift through vertical shafts in stormwater conduits. J. Water Manag. Model. 2012. [CrossRef]

15. Padulano, R.; Del Giudice, G.; Carravetta, A. Experimental analysis of a vertical drop shaft. Water 2013, 5, 1380. [CrossRef]

16. Bousso, S.; Daynou, M.; Fuamba, M. Mixed flows with depressurizing wavefront in circular pipe. J. Irrig. Drain. Eng. 2014, 140. [CrossRef]

17. Cardie, J.A.; Song, C.C.; Yuan, M. Measurements of mixed transient flows. J. Hydraul. Eng. 1989, 115, 169-182. [CrossRef]

18. Baines, W.D. Air cavities as gravity currents on slope. J. Hydraul. Eng. 1991, 117, 1600-1615. [CrossRef] 
19. Ramezani, L.; Karney, B.; Malekpour, A. Encouraging effective air management in water pipelines: A critical review. J. Water Resour. Plan. Manag. 2016, 142, 04016055. [CrossRef]

20. Hatcher, T.M.; Vasconcelos, J.G. Experimental study on scale effects in surges caused by sudden air pocket entrapments. In Proceedings of the World Environmental and Water Resources Congress 2014, Portland, OR, USA, 1-5 June 2014; pp. 1282-1291. 